\title{
LOGÍSTICA DE UMA COOPERATIVA EXPORTADORA: ESTUDO DE CASO DOS PROCESSOS INTERNOS E EXTERNOS
}

\author{
Driele Cendon Trindade \\ Especialista em Logística Empresarial - FARN \\ Graduada em Tecnologia em Comércio Exterior - CEFET-RN \\ Graduada em Tecnologia em Lazer e Qualidade de Vida CEFET-RN \\ E-mail: drieleee@yahoo.com.br \\ Renato Samuel Barbosa de Araújo \\ Professor de educação profissional em nível médio e graduação - CEFET-RN \\ Doutor em Engenharia de Produção - COPPE-UFRJ \\ Mestre em Engenharia Mecânica - UFRN \\ Graduado em Engenharia Civil - UFRN \\ E-mail: renato@cefetrn.br
}

\begin{abstract}
RESUMO
O Comércio Internacional vem sofrendo grandes transformações ao longo dos anos, na atualidade é mais fácil comprar um produto importado com qualidade igual, inferior ou superior aos produtos nacionais do que há vinte anos atrás. Essa facilidade gerou uma grande competitividade dos produtos de consumo, mas também abriu as portas para muitas empresas se inserir no mercado internacional. Dessa forma, o cooperativismo surge como uma alternativa para empresas que desejam adentrar nesses mercados minimizando custos e barreiras tarifárias. Nessa perspectiva, a logística das empresas - que integram desde a compra de insumos à distribuição final da mercadoria - possui fatores determinantes para essa inserção, em vantagens como: otimizar a produção e aprimorar os processos em todos os setores das empresas e também na exportação de produtos. Assim, este estudo apresenta um panorama do funcionamento logístico de uma cooperativa exportadora de produtos de moda praia. $\mathrm{O}$ objetivo central é expor a logística interna das empresas que compõem a referida cooperativa. Adicionalmente descreve-se a logística da cooperativa exportadora e avalia-se a influência da logística formação do preço final. O estudo foi conduzido valendo-se de pesquisa investigativo-exploratória com revisão bibliográfica, e para a pesquisa de campo utilizou-se questionários semi-estruturados. Conclui-se apontando os principais processos logísticos que contribuem decisivamente para o crescimento e fortalecimento de uma cooperativa, como atividade econômica.
\end{abstract}

Palavras-Chave: Cooperativa exportadora. Logística interna. Logística externa.

\section{LOGISTICS OF ONE EXPORTER COOPERATIVE: A RESEARCH OF INTERNAL AND EXTERNAL PROCESSES}

\begin{abstract}
The International Trade has been experiencing great changes over the years, in actuality it is easier to buy an imported product with equal quality, lower or higher than the domestic products than twenty years ago. This facility has generated a great competitiveness of consumer products, but also opened the doors to many companies entering the
\end{abstract}


international market. Thus, the cooperative is emerging as an alternative for companies wishing to enter these markets minimizing costs and tariff barriers. Accordingly, the logistics businesses - which comprise from the supply chain to final distribution of the goods - has determining factors for such inclusion, in advantages such as: to optimize production and improve the processes in all sectors of business and also in the export of products. Thus, this study presents an overview of the functioning of a cooperative logistics export of products of beach fashion. The central objective is to explain the logistics of domestic companies that make up the cooperative. Additionally describes itself to cooperative logistics of exporting and to assess the influence of logistics training of the final price. The study was conducted is worth the search investigative and exploratory with literature review, and to search the field used to semi-structured questionnaires. It is pointing the main logistics processes that contribute decisively to the growth and strengthening of a cooperative, as economic activity.

Key-Words: Cooperative Export, Logistics Affairs, Foreign Logistics.

\section{LOGÍSTICA DE UMA COOPERATIVA EXPORTADORA: ESTUDO DE CASO DOS PROCESSOS INTERNOS E EXTERNOS}

\section{INTRODUÇÃO}

A logística, segundo Michaelis (2007, p.83), pode ser compreendida como "Ciência militar que trata do alojamento, equipamento e transporte de tropas, produção, distribuição, manutenção e transporte de material e de outras atividades não combatentes relacionadas", pois surge em um período de conflitos e guerras, onde as tropas necessitavam se locomover e se adequar aos meios, dando início a uma imensa fração de atividades específicas elaboradas para melhor acondicionar, armazenar e transportar material essencial aos combates e adjacentes.

Atualmente a logística perdeu esse status para finalidades de guerra e passou a fazer parte de todos os processos internos e externos das organizações, estando presente desde a aquisição de matéria-prima, chegando à logística reversa.

Ainda é difuso o significado atual, pois geralmente é aliado aos transportes devido ao fato de ser a parte mais visível do processo, pois é o que leva os insumos para a produção, e a mercadoria da produção para o destino final; e também por ser o fator de maior custo. A Logística pode ser entendida como um processo contínuo que faz parte de toda cadeia produtiva: planejamento, implementação, produção e distribuição.

Vários teóricos definem a logística, dentre os quais podem ser citados: Ching (1999), para o qual a logística é um canal de distribuição e é entendida como sendo a cadeia de suprimentos; já para Christopher (1997), logística é como um processo; para o IMAM (2008), um sistema, e para Ballou (1993) trata de atividades de movimentação e armazenagem até o consumidor final.

Neste estudo adota-se o conceito de Ballou, por se entender como o referente ao uso atual:

A logística empresarial trata de todas as atividades de movimentação e armazenagem, que facilitam o fluxo de produtos desde o ponto de aquisição da matéria-prima até o ponto de consumo final,..., com propósito de providenciar níveis de serviço adequados aos clientes a um custo razoável. (1993, p. 24) 
Percebe-se com essa definição a necessidade de uma visão geral de todo o processo produtivo. Esta definição é completa, pois privilegia e coloca como foco da logística o atendimento das necessidades dos consumidores. A interferência da logística dissemina informações pertinentes sobre o cliente final e estimula o crescimento das empresas e conseqüentemente dos setores.

Tendo em vista o crescimento dos setores surge a atividade Cooperada, em que as empresas deixam de atuar de forma individual e passam a agir em sociedade com atividade econômica comum, possibilitando a produção e manutenção de todos os associados, contribuindo diretamente para o crescimento das mesmas de forma igualitária tanto com relação aos direitos, quanto deveres, regidos por estatuto social próprio.

Assim, estudar o processo logístico dentro de uma atividade de cooperativismo é relevante, pois possibilita a visão de duas atividades interligadas. A primeira, das empresas que formam a cooperativa, que possuem seus próprios métodos e sendo empresas definidas como tal, sua produção independente. E a segunda, as atividades logísticas da cooperativa exportadora em si, de forma a agregar todos os produtos como sendo uma única pessoa jurídica, responsável, através de uma marca representativa.

Dessa forma, a atividade logística tem vantagens relevantes para o contexto a ser estudado, principalmente com relação à redução dos custos com transportes, menores gastos com impostos, tarifas e tributos incidentes, além de aumentar o poder de barganha com os fornecedores, não incidindo sobre a atividade exportadora o Programa de Integração Social (PIS) e a Contribuição para o Financiamento da Seguridade Social (Cofins), tendo o ICMS - Imposto Sobre Circulação de Mercadorias e Prestação de Serviços - suspenso.

É imprescindível entender o processo interno e externo de logística, se diferenciando no canal de distribuição. A logística interna refere-se à movimentação, manuseio, manutenção, armazenagem, e cadeia de suprimentos dentro da própria empresa. Enquanto a logística externa refere-se a toda movimentação de mercadoria de uma empresa para outra ou para o consumidor final.

Assim, tem-se como objetivos identificar as ações logísticas internas das empresas que compõem uma cooperativa e as ações logísticas externas da própria cooperativa enquanto empresa exportadora relacionando-as, bem como e a influência da logística na formação do preço do produto.

O presente estudo justifica-se pela necessidade de ampliar o debate da prática empírica, desmistificando a premissa de que logística é transporte, e sim, está ligada a toda cadeia produtiva; por ser uma área complexa, exige profissionais especializados e capacitados para atender a demanda de mercado do planejamento à execução; e pela escassez de formação de cooperativas exportadoras no estado, o que contribuiria para aumentar a pauta exportadora.

O estudo foi realizado na Cooperativa Cactus Brasil, de forma investigativo-descritiva por ser baseada em dados colhidos in loco, através do instrumento de pesquisa; e constante pesquisa bibliográfica, buscando a interação entre a teoria e a visualização prática acerca das atividades desenvolvidas no período de março/agosto 2008. 
Diante de tais considerações acerca de Logística e de Cooperativismo, este estudo abordará em seus capítulos uma explanação sobre os assuntos envolvidos, tais como uma abordagem sobre logística e sua contextualização, a formação de cooperativas, logística interna e externa de uma cooperativa exportadora, e a interferência da logística na formação do preço dos produtos, análise e apresentação dos dados; considerações finais e recomendações.

\section{CONSIDERAÇÕES ACERCA DAS QUESTÕES LOGÍSTICAS}

\section{LOGÍSTICA CONTEXTUALIZADA}

Até o fim da Segunda Guerra Mundial a logística esteve associada às atividades militares transportes de material bélico, de recursos para abastecimento da frota, planejamento das ações, organização e execução de ordens, definição de rota, armazenagem, distribuição de equipamentos e suprimentos. Após esse período, com o avanço tecnológico e a necessidade de suprir os locais destruídos pela guerra, a logística passou a ser adotada pelas empresas, Ballou (1993).

No Brasil, o uso do termo "logística" iniciou a partir dos anos 50, quando as empresas começaram a se preocupar com a satisfação do cliente, surgindo então o conceito de logística empresarial, motivado por uma atitude do consumidor de exigir da atividade logística no país e no mundo, passando por um controle maior de identificação de oportunidades, redução de custos, redução nos prazos de entrega, aumento da qualidade, cumprimento dos prazos, disponibilidade constante dos produtos, programação das entregas, facilidade na gestão dos pedidos e flexibilização da fabricação, análises de longo prazo com incrementos em inovação tecnológica, novas metodologias de custeio, novas ferramentas para redefinição de processos e adequação dos negócios, entre outros. A partir de então a realidade atual da atividade logística desatrelou-se do caráter militar, e abrange as funções gerenciais das empresas e de todos segmentos fabris, comerciais ou de serviços.

\section{ENTENDENDO A LOGÍSTICA INTERNA}

De acordo com Keedi (2004), os processos logísticos devem responder a questões fundamentais, como: qual a melhor forma de entregar um produto? Onde ele deve ser entregue? Quais os modais de transporte a serem utilizados? Que serviços podem ser apresentados ao comprador e a que preço? O produto é competitivo em nível internacional? Sem essas premissas não é possível fazer um planejamento dos recursos utilizados para a efetivação de um contrato, no caso, o contrato de compra e venda.

Em resumo, logística é a arte de comprar, receber, armazenar, separar, expedir, transportar, e entregar o produto/serviço certo, na hora certa, no lugar certo, ao menor custo possível, verificando que está inserida em toda cadeia da empresa.

Esses processos atualmente são tão complexos e fazem parte de todo setor produtivo, administrativo e executivo das empresas, que foi necessário subdividi-los em dois tipos de atividades; as atividades principais: transportes, manutenção de estoques, e processamento 
de pedidos, cosideradas assim porque são de importância primária para atingir os objetivos logísticos de custo e nível de serviço, e as atividades secundárias ou de apoio sendo: armazenagem, manuseio de materiais, embalagem, suprimentos, planejamento e sistema de informação.

O Transporte diz respeito ao movimento de pessoas e mercadorias de um local para outro, um dos que mais influencia no custo total, sendo essencial para o destino final dos produtos/serviços; A Manutenção de Estoques - possibilita entregar o produto ao cliente assim que acaba sua fabricação, no menor tempo possível, dependendo do deslocamento, os estoques agem como "amortecedores entre a oferta e a demanda" sendo considerados peças-chaves para a logística, o chamado Lead-Time; O Processamento de Pedidos - é um elemento crítico em termos do tempo necessário do início da movimentação de produtos e a entrega de serviços aos clientes.

As atividades secundárias ou de apoio, são: Armazenagem - que é o ato ou efeito de guardar, juntar produtos em algum lugar de forma que seja possível resgatá-los, consultálos, usá-los posteriormente; Manuseio de Materiais - as tecnologias de movimentação do processo com um mínimo de distúrbios na capacidade e fluxo; Embalagem - como o produto é apresentado graficamente considerando problemas de ergonomia e estética tridimensional; Suprimentos - devem ser entregues no exato momento em que eles são necessários na produção, especialmente dentro dos conceitos de "just-in-time"; Planejamento - é um processo administrativo que visa determinar a direção a ser seguida para alcançar um resultado desejado; Sistema de Informação - um sistema automatizado, que abrange pessoas, máquinas, e/ou métodos organizados para coletar, processar, transmitir e disseminar dados que representam informação para o usuário.

Assim, definidas as atividades da logística, percebe-se que as primárias e de apoio se complementam, cada uma no seu propósito, sendo uma essencial para a realização e efetividade da outra.

\section{A FORMAÇÃO DE UMA COOPERATIVA}

Muitas empresas possuem dificuldades em administrar suas contas, insumos, produção e principalmente abastecimento, quando a demanda por seus produtos é maior que a oferta, na prática, é propício o surgimento do cooperativismo.

O cooperativismo pode ser entendido como uma atividade social que converge atividades econômicas comuns, para integrar formas de benefício mútuo entre empresas de mesmo segmento. O fim maior desse tipo de organização é o homem, não o lucro. Uma organização dessa natureza caracteriza-se por ser gerida de forma democrática e participativa, de acordo com aquilo que pretendem seus associados.

A atividade cooperada responsabiliza todos os seus membros, mediante estatuto social regulamentado. Nesse, deve incluir em linhas gerais: a forma de funcionamento, mencionar as obrigações e direitos dos associados, eleição dos administradores, modo de administração e fiscalização, definição de atribuições e poderes, representação ativa e passiva da sociedade em juízo ou fora dele, entre outras, dando inicio a formação de uma Cooperativa. 
Uma cooperativa é formada por um grupo de vinte pessoas no mínimo com o objetivo de desenvolver uma atividade econômica ou prestar serviços comuns, eliminando os intermediários. É constituída de reunião para tomada da decisão de implementação, planejamento, elaboração da proposta de Estatuto Social, assembléia geral de constituição da cooperativa com Ata Constitutiva, registro do estatuto no cartório de registro civil das Pessoas Jurídicas, na Secretária da Receita Federal, e na SEFAZ - Secretaria da Fazenda -, e por fim o registro no Sistema OCB - Organização das Cooperativas Brasileiras-, tendo direito em receber assessorias jurídica e contábil, treinamentos de capacitação e de gestão.

Uma vez criada a cooperativa, seus associados passam a ter benefícios, direitos e deveres comuns, dos quais passam a ser regidos e regulamentado seu funcionamento pela Lei Federal $\mathrm{N}^{\mathrm{o}}$ 5.764/71, e Lei Federal $\mathrm{N}^{\mathrm{o}}$ 10.406/02. É um sistema no qual um grupo de pessoas mantém uma empresa de propriedade coletiva e gerida de forma participativa.

As vantagens de se criar uma cooperativa podem ser descritas como: aumentar a escala de produção; maior produtividade; melhorar os seu poder de barganha com fornecedores; reduzir os custos administrativos, operacionais e tributários, visto que o Poder Judiciário reforça a tese de não caber incidência do Programa de Integração Social (PIS) e da Contribuição para o Financiamento da Seguridade Social (Cofins).

O capital social de uma cooperativa é formado por quotas-partes dos cooperados, eles devem integrar um valor mínimo que formará o capital social da cooperativa, podendo receber doações, empréstimos e processos de capitalização, além do aumento do crédito. Isso facilita os processos diretos de financiamentos junto às instituições financeiras.

Dessa forma, visualiza-se neste estudo, a tendência a se estudar a formação de cooperativas, pois muitas micro e pequenas empresas, artesãos e trabalhadores informais possuem dificuldades de honrar seus contratos, sejam formais ou informais. Essa forma de negócio faz com que os empreendedores deixem de ser competitivos diretamente entre si, e passem a conseguir juntos através da cooperativa: ampliação de recursos, demanda, estabelecimento próprio, local de fábrica, pessoa jurídica entre outros benefícios que isoladamente seria mais árduo, ou mesmo burocraticamente impossível de ser aprovado.

\section{LOGÍSTICA INTERNA DAS EMPRESAS QUE FORMAM UMA COOPERATIVA}

Para uma cooperativa, a logística interna diz respeito diretamente a logística utilizada pelas próprias empresas associadas. Essas produzem como uma empresa única, diferenciando seu modo de distribuição, funcionando a cooperativa, de certa forma, como um intermediário ao destinatário.

As empresas precisam processar informações, desenvolver fornecedores, acionar compras, receber e verificar materiais, embalar e movimentar produtos, estocando-os apropriadamente para preservar sua integridade. É preciso, ainda, planejar e controlar estoques e produção, movimentar e estocar mercadorias, otimizar layouts e fluxos de materiais e pessoas, qualificar colaboradores e parceiros, medir e gerenciar custos, avaliar e auditar a qualidade, entre outros. 
Faz parte da logística interna das empresas a maneira como o insumo chega ao produtor, como é feita a distribuição de material internamente, o tempo de produção, acabamento, entre outros. É essa logística que faz com que a organização obtenha vantagem competitiva perante seus concorrentes; é preciso sincronizar e harmonizar todos os elementos que compõem a logística, principalmente interna.

\section{A OBTENÇÃO DA MATÉRIA-PRIMA}

As empresas que formam a cooperativa, podem se unir de forma a comprar matéria-prima comum e distribuí-la entre os associados, ou mesmo cada associado adquirir os insumos necessários para sua produção.

É muito comum a utilização da compra de matéria-prima por parte da cooperativa para seus associados, principalmente quando o produto exige um padrão de qualidade e paridade frente à demanda, como exemplo confecções de moda praia, cuja malha é essencial para a finalização e qualidade do produto acabado, assim como a tinta especial para bordados, pigmento especial para coloração de T-shirts, entre outros.

A formação de cooperativa facilita a obtenção de matéria-prima, pois tem poder de barganha maior para negociar com os fornecedores, visando atender a produção de modo mais eficaz e o cumprimento de metas especificas com relação a prazos, qualidade e volume adquirido pelos clientes.

\section{O PRODUTO}

Como a função da logística está centrada na gestão do produto, sua definição é importante, pois, só será produto, o que bem atender às necessidades do cliente, no momento e na forma como solicitado. Não se encaixando nesses aspectos, será algo fora dos padrões, tornando-se desnecessário, não sendo comercializado.

Assim, Produto é entendido como meio pelo qual as empresas buscam atingir seus objetivos, constituindo-se em um bem físico que se pretende disponibilizar ao cliente.

Cada produto possui características próprias, como volume, peso, qualidade, conveniência, além da capacidade de substituir outros. Para a logística, cada uma dessas características influencia no preço final do produto final.

\section{LOGÍSTICA EXTERNA DE UMA COOPERATIVA EXPORTADORA}

Assim como a logística interna define como as empresa organizarão seus produtos por meio do tempo de fabricação, embalagens, estoques, entre outros, a logística externa liga os empresários - representados aqui pela Cooperativa - diretamente ao mercado-alvo dos seus produtos. 
A logística como visto anteriormente, é um dos processos mais caros para a exportação, pois os custos dos transportes, além da distância, variam, também, de acordo com o produto, como: valor da mercadoria, quantidade, risco, peso, entre outros. Portanto, fica clara a importância da utilização adequada dos transportes e a que melhor irá satisfazer as necessidades do importador, Ballou (1993).

Perceptível também é o fato de que embora as empresas se unam para formar a cooperativa exportadora, para o mercado interno funcionam como empresas normais, destinando uma parte de sua produção para a venda doméstica, Christopher (1997). É importante que as empresas tenham uma parcela da produção para o mercado nacional, visto que as crises internacionais podem afetar diretamente o produtor, fazendo com que despenque o preço causando a falência de empreendimentos, como caso do camarão quando taxado pelo governo Norte-americano e de algumas empresas norte-riograndenses de moda praia que se baseavam somente na exportação.

É importante ter essa visão de como a cooperativa funciona quanto à logística externa, unindo a produção dos seus associados: o produto pronto ou mesmo in natura e destinando ao mercado internacional de forma direta, sem atravessadores ou agentes representantes, pois a logística de uma cooperativa é uma das formas mais complexas de negócios quando se trata de comércio internacional e seu funcionamento é singular.

\section{A ESCOLHA DO INCORTEM - TERMOS INTERNACIONAIS DO COMÉRCIO}

Os International Commercial Terms ou Termos Internacionais do Comércio auxiliam no fechamento dos negócios internacionais, tendo em vista as responsabilidades das partes interessadas: exportador e importador. Surgiram em 1936 quando a Câmara Internacional do Comércio interpretou e consolidou os contratos de compra/venda aperfeiçoando constantemente as nomenclaturas culminando com um novo conjunto de regras, conhecido atualmente como Incoterms 2000 (Incoterms, 2000).

Esses termos são defendidos juridicamente uma vez firmados em contrato - Fatura Comercial ou Commercial Invoice-, simplificam e agilizam a elaboração das cláusulas dos contratos de compra e venda, ficando a cargo das partes decidir qual o melhor Incoterm caberá utilizar na negociação para um beneficiamento mútuo.

Em termo gerais, são definidos desde o que possui maior responsabilidade do exportador ao que possui maior responsabilidade do importador, atualmente contamos com treze regras definidas pelo Incoterms 2000, de acordo com seus grupos de obrigações. Grupo E: de Ex (Mínima obrigação para o exportador) -> EXW - Ex Works -> O importador é responsável por transportar a mercadoria desde a fábrica do exportador. Grupo F: de Free (Transporte principal pago pelo importador) -> FCA - Free Carrier, FAS - Free Alongside Ship, FOB - Free on Board -> O frete internacional é de responsabilidade do importador, normalmente pago no destino à companhia transportadora. Grupo $\mathbf{C}$ : de Cost ou Carriage (Transporte principal pago pelo exportador) -> CFR - Cost and Freight, CIF - Cost, Insurance and Freight, CPT - Carriage Paid To, CIP - Carriage and Insurance Paid to -> O transporte internacional é de responsabilidade do exportador, geralmente embutido no preço final da mercadoria. Podendo ser segurado ou não, assumindo os riscos por perdas ou danos às mercadorias ou custos adicionais decorrentes de eventos ocorridos após o 
embarque e despacho. Grupo D: de Delivery (Máxima obrigação para o exportador) -> DAF - Delivered At Frontier, DES - Delivered Ex-Ship, DEQ - Delivered Ex-Quay, DDU - Delivered Duty Unpaid, DDP - Delivered Duty Paid $\rightarrow$ O exportador é responsável por todos os custos e riscos para entregar a mercadoria no destino. Para uma melhor visualização, segue a figura 1 .

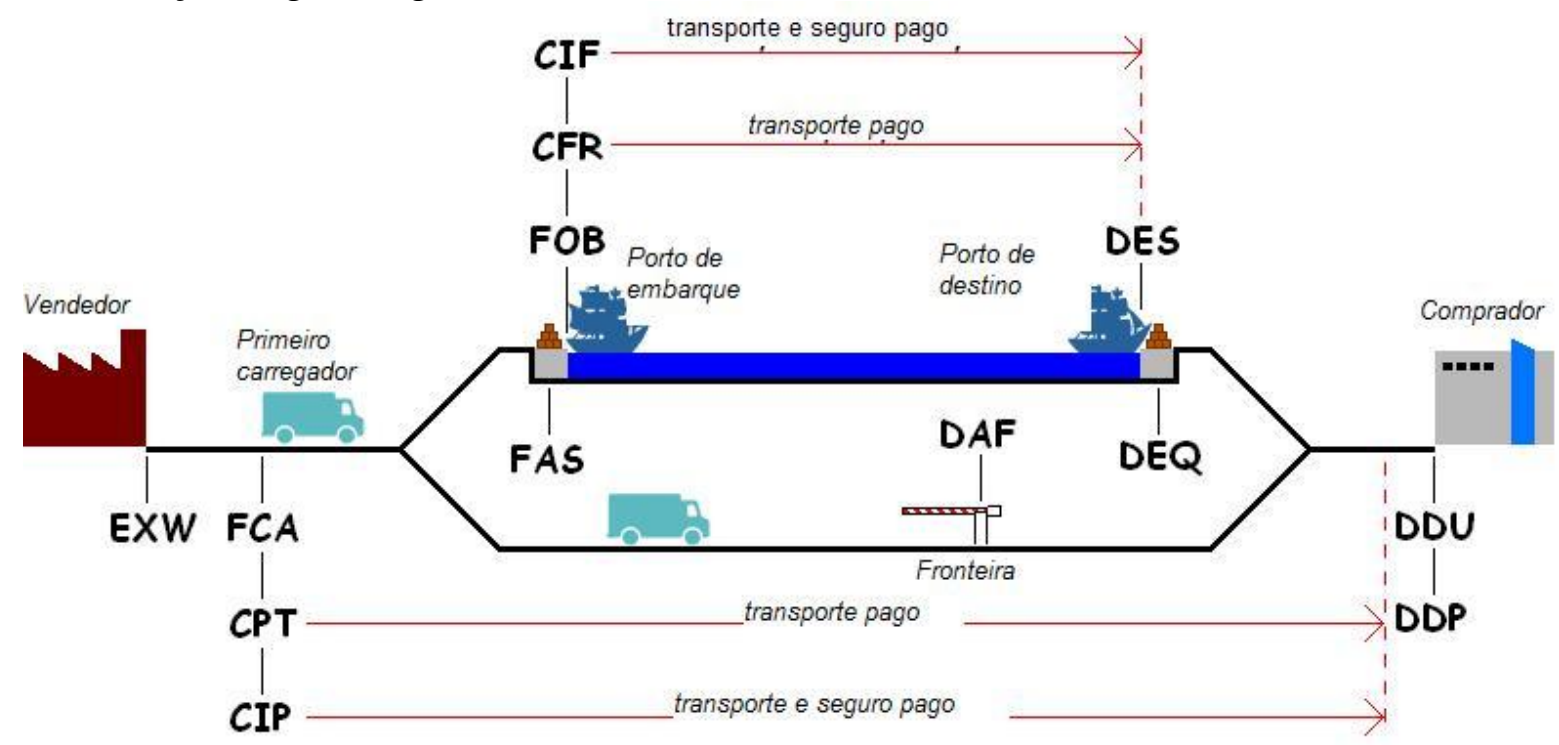

Figura 1 - Transferência de Risco do Vendedor ao Comprador Fonte: Incoterms 2000.

Os Incoterms são instrumentos usuais, com vistas e minimizar as diferenças entre as partes interessadas. São regras, que visam à uniformização e harmonização dos contratos internacionais de comércio, na qual uma vez agregados aos contratos passam a ter força legal e incidem diretamente no valor aduaneiro da mercadoria.

\section{A UTILIZAÇÃO DOS TRANSPORTES NA LOGÍSTICA INTERNACIONAL}

A escolha dos transportes é decisiva para a logística de uma empresa. Muitas empresas perdem contratos internacionais, por não cumprirem os acordos de entrega devido ao mau uso dos transportes, ou estabelecendo prazos dos quais os modais escolhidos não atendem às expectativas do importador, ficando com o exportador o prejuízo da negociação fracassada ou mesmo mal feita.

Os meios de transportes conhecidos são os: ferroviário, rodoviário, aquaviário - marítimo e fluvial-, dutoviário e aéreo, caracterizados por diferenças, como: velocidade, disponibilidade, confiabilidade, capacidade, preço e frequiência, determinando, conforme sua escolha, o preço agregado ao produto final, tornando o produto mais barato ou mais caro, Keedi (2004).

Entender a questão dos transportes não é apenas como o produto chegará ao país de destino, mas sim, desde os insumos que chegam ao exportador para sua produção, ao envio para o mercado internacional, e como será feita a entrega ao importador. Para isso é importante frizar que em contratos internacionais normalmente utilizam mais de um modal de transporte, normalmente sendo combinado o marítimo/rodoviário visto que os 
importadores nem sempre importam/exporta mercadorias pelo o porto mais próximo (exemplo é que a maioria das empresas de frutas do Rio Grande do Norte embarca seus produtos por Pecém/CE, ou Suape/PE).

Assim, é essencial compreender e estar atendo às necessidades de transporte de mercadorias, principalmente quando perecíveis. Dessa maneira, fica claro que o empresário deve escolher bem os modais a serem utilizados para a disseminação do seu produto, não tendo prejuízos tanto com a mercadoria, quanto com os importadores.

\section{A INTERFERÊNCIA DA LOGÍSTICA NA FORMAÇÃO DO PREÇO}

A logística é um dos componentes que mais influencia na definição do preço final. É importante ter base nos preços gerais de gastos com todos os setores produtivos para ter noção do preço de fabricação, atribuindo em cima deste, o lucro desejado.

Existem duas vertentes para definir o preço do produto: valor presumido de um produto - a fixação do preço baseia-se na percepção que se tem com relação a determinado grupo de produtos que, por serem exóticos ou únicos, parecem mais caros para os consumidores; e, seguir o líder - este é um método menos arriscado em que os preços são fixados com base nos praticados pelos líderes do mercado.

Apesar de ser menos arriscado, estipular o preço de acordo com o líder do mercado, pode ser um suicídio para a empresa, já que não se tem uma clara visão dos custos agregados que determinarão tal decisão para a formação do mesmo. O exportador deve ter a noção de que o preço define a classe a qual o produto se destina.

Dentro das normas de uma cooperativa, seus associados devem estabelecer um preço a ser praticado por todas as empresas. Essa política garante o lucro comum e a firmação de contratos entre todas as partes de maneira igualitária, por isso que as empresas que compõem a cooperativa devem ter produtos com as mesmas qualidades e padrões.

Fatores como: custo das matérias-primas, produtos intermediários e materiais de embalagens, sem IPI e ICMS, custo de mão-de-obra e encargos sociais, custos administrativos, custos fixos, frete e seguro internos, transporte, custos aeroportuários ou de embarque, custos de despachante, custos bancários, custos, margem de lucro, imposto de renda sobre lucro, comissão de agentes, vistos consulares, despesas de publicidade no exterior, custo do seguro de crédito à exportação, despesas com frete e seguro (INCOTERMS, 2000), são decisivos e compõem as despesas de produção, e devem ser repassados ao consumidor mais o lucro estimado.

Muitas empresas não apuram seus custos e despesas de maneira precisa e os preços de venda são obtidos empiricamente, essa prática mascara os custos e o lucro da empresa, acarretando muitos problemas, tais como: preço de venda abaixo do real - o que diminui a margem de lucro -, preço de venda acima do real - o que dificulta a venda -, fabricação de produtos com pouco lucro - ocasionando má alocação de recursos -, esforço de venda não orientado para produtos mais lucrativos -, dificuldades para identificar e fixar alternativas para redução de custos - o que leva a empresa a gastar mais do que deveria com a 
produção, indicando que há uma logística ineficiente na empresa e que precisa ser melhor planejada.

Dentre as várias incidências para a determinação de um preço em nível internacional, o mesmo só será competitivo se atender às necessidades do importador, tendo em vista compensar buscar o produto em outro país, seja pela qualidade, quantidade, prazos, entre outros. Deve-se sempre considerar o que o cliente está disposto a pagar pelo produto.

\section{ANÁLISE E APRESENTAÇÃO DOS DADOS: SETOR DE MODA PRAIA}

O Brasil sempre teve uma grande desenvoltura no setor têxtil, destacando-se pelo avançado nível tecnológico empregado na fabricação de tecidos e criatividade de diversificação de produtos.

A evolução do setor têxtil brasileiro tem passado por diversas fases. A desvalorização cambial do dólar e do euro, além da entrada da China como concorrente principal de todos os países exportadores de tecido, alta carga tributária, alta burocracia, entre outros, fizeram com que o setor sofresse variações consideráveis, incluindo a perda de mercados externos.

No Rio Grande do Norte, a realidade não é diferente do país. As mesmas dificuldades encontradas em âmbito nacional, também podem ser vinculadas ao estado e ainda a mãode-obra não qualificada como sendo os principais motivos das variações de vendas externas.

Essas variações no estado do Rio Grande do Norte podem ser quantizadas de acordo com a Tabela 1 a seguir, a qual mostra a variação das exportações do setor entre 2002 e maio de 2008.

\begin{tabular}{ccc}
\multicolumn{3}{c}{ Tabela 1 - Variação das Exportações de Tecidos no RN } \\
\hline TECIDO/ ANO & VENDAS EM US\$ FOB & VARIAÇÃO \\
\hline 2002 & 5.745 .422 & - \\
2003 & 5.357 .467 & $-7,0$ \\
2004 & 8.940 .163 & 68,39 \\
2005 & 14.769 .332 & 62,50 \\
2006 & 12.156 .989 & $-17,69$ \\
2007 & 7.170 .336 & $-41,02$ \\
2008 & 1.204 .745 & $-83,20$
\end{tabular}

Fonte: Adaptado da FIERN

De acordo com a tabela acima, percebe-se que a variação cambial foi fator decisivo para a queda das exportações (em maio/2007 o dólar iniciou desvalorização abaixo de R \$2,00, de acordo com o $\mathrm{BACEN}^{1}$ ), pois a logística de transportes para adquirir um produto brasileiro não se torna atrativa diante do alto custo do frete internacional, fazendo com que os importadores adquiram produtos de localidades mais próximas.

Ainda para dificultar a comercialização dos produtos brasileiros, por meados de outubro de 2008 se alastrou uma crise internacional afetando todos os mercados e setores mundiais, devido à uma crise de crédito iniciada nos EUA que rapidamente afetou a economia de 
todos os países, pois os EUA são considerados um dos maiores consumidores de produtos importados no mundo.

Entretanto, o país está conseguindo criar alternativas para não perder negócios internacionais, superar a desvalorização cambial do dólar, e enfrentar seus concorrentes com qualidade, valor agregado e criatividade, se destacando em Feiras Internacionais e Rodadas de Negócios. Uma dessas alternativas é o segmento de Moda Praia.

Nas considerações de CAMPELO (2007), a Moda Praia brasileira atualmente é uma das principais mercadorias da indústria de confecções na pauta exportadora do país, ao lado do jeans. É um dos segmentos que mais cresce no mercado internacional tendo como principais importadores os países da União Européia.

Tal segmento vem crescendo e contribuindo para a balança comercial do RN significativamente, sendo foco de vários estudos e projetos governamentais, como políticas públicas e privadas de incentivos e carga tributária diferenciada.

As empresas desse segmento se tornaram competitivas no decorrer do tempo, em nível internacional, devido a condições favoráveis pela boa imagem do produto no exterior, mão-de-obra barata, matéria-prima acessível, qualidade na produção e uso de alta tecnologia, produzindo tecidos mais resistentes e confortáveis.

1 - Banco Central do Brasil, taxa extraída na conversão da moeda Real para o Dólar americano do dia 15 maio 2007 , disponível em: http://www5.bcb.gov.br/pec/conversao/Resultado.asp?idpai=convmoeda. Acesso em 18 jul 2008.

Diante de tais considerações, muitas empresas do segmento aproveitaram o incentivo do Governo e as oportunidades do setor que se destacava no cenário internacional desde 2002, inserindo-se no mercado externo, como as empresas do consórcio Cactus Brasil no Rio Grande do Norte: Nippe, Potala, Ruddow e Artesol, expandindo seus mercados a partir de 2005 .

\section{A COOPERATIVA}

A Cooperativa da marca Cactus Brasil foi idealizada por empresário do segmento de moda praia, que participavam de Feiras Internacionais e Rodadas de Negócios para expor seus produtos individualmente. Essas empresas visualizaram a necessidade de atrelar seus produtos a uma marca, para melhor identificação e vendas no mercado externo, iniciou-se então a Cooperativa com 7 empresas, e atualmente o grupo é formado por 4.

Os empresários identificaram que era mais viável apresentar e vender um produto aos importadores de forma mais estruturada, pois o espaço disponibilizado para a exposição em Feiras Internacionais com o apoio da APEX - Agência de Promoção às Exportações e Incentivos - era pequeno, e era visualmente pouco atrativo ter várias etiquetas e apresentação de coleções diferentes. Dessa forma, algumas empresas se juntaram com apoio do SEBRAE em 2005, dois meses antes da Feira em Madrid e resolveram criar a mesma etiqueta.

A formação da Cooperativa facilitou as vendas internacionais, pois através das feiras os empresários conseguiram fechar um maior volume de negócios com maior quantidade de 
peças, distribuindo melhor sua fabricação e atendendo aos prazos dos importadores, além de diminuir os custos para cada empresário de expor os produtos.

Atualmente a Cooperativa conta com um acervo de 100 peças para exposições em Feiras Internacionais, e já apresentaram suas coleções nas Feiras de Madrid em 2005, Lion e Madrid em 2006, Lion e Madrid em 2007 e Paris e Madrid em 2008, e outros eventos de Moda no Sul da França, México e na África.

O empreendimento é formalizado, possuindo CNJP, mas não se utilizam da Lei de Cooperativas e também não possuem regimento interno e estatuto. Tais, não se fazem necessários, pois as empresas só se juntam para produzir peças destinadas exclusivamente para exportação.

A Cooperativa é caracterizada como média empresa, de acordo com a classificação da ANVISA, por receita operacional bruta anual, constituída de capital próprio, e cada empresa do grupo é uma microempresa, de organização familiar de acordo com o Estatuto de Micro e Pequena Empresa (conforme Lei Complementar $n^{\circ} 123$, de 14 de dezembro de 2006) - Tabela 2.

Tabela 2 - Porte de Empresas - ANVISA e LEI COMPLEMENTAR no 123/06

\begin{tabular}{|c|c|c|}
\hline PORTE & $\begin{array}{c}\text { RECEITA OPERACIONAL } \\
\text { MÍNIMA }\end{array}$ & $\begin{array}{c}\text { RECEITA OPERACIONAL } \\
\text { MÁXIMA }\end{array}$ \\
\hline Microempresa & - & $\mathrm{R} \$ 240.000,00$ \\
\hline $\begin{array}{c}\text { Pequena } \\
\text { Empresa }\end{array}$ & $\mathrm{R} \$ 240.000,00$ & $\mathrm{R} \$ 2.400 .000,00$ \\
\hline Média Empresa & $\mathrm{R} \$ 2.400 .000,00$ & $\mathrm{R} \$ 20.000 .000,00$ \\
\hline Grande Empresa & $\mathrm{R} \$ 20.000 .000,00$ & - \\
\hline
\end{tabular}

Fonte: Lei Complementar $\mathrm{n}^{\circ}$ 123, de 14 de dezembro de 2006, disponível em: https://www.planalto.gov.br/ccivil_03/leis/lcp/lcp123.htm, Acesso em 15 jul de 2008, e ANVISA. Disponível em: http://www.anvisa.gov.br/servicos/arrecadacao/porte.htm

\section{Acesso em: 15 jul de 2008.}

A organização não possui um dirigente direto, visto que todos os gestores atuam em suas empresas individuais e respondem pelos acordos firmados como partes contratadas da mesma forma. Sendo assim, a administração é participativa, de forma que todos os empresários são os próprios diretores, decidem coleções, fabricam, elaboram os designs das coleções e tomam decisões de forma informal caso ocorra algum imprevisto.

A Cooperativa enfrenta muitos problemas burocráticos, mas segundo os entrevistados, o que mais dificulta é a segregação da produção, pois cada empresa tem seu próprio local de confecção, destinando uma parte à exportação. Dessa maneira, com a fabricação das peças separadas surgem muitos problemas que acarretam custos maiores.

O volume de vendas no mercado internacional varia muito de acordo com a estação, como é um produto sazonal, só é vendido no verão. As coleções demoram cerca de 3 a 6 meses desde seu planejamento à execução e entrega ao cliente. As empresas trabalham cerca de 3 meses por ano exclusivamente para exportações, pois o número de pedidos varia de 300 a 800 peças por importador, feitas somente por encomenda, principalmente por negócios fechados através das Feiras Internacionais; cada ano é feita apenas uma coleção para apresentação nessas Feiras. 
Essa coleção é montada da seguinte forma: os próprios empresários buscam tendências de mercado, pesquisas, o que vai estar na moda, cores, padrões, modelagens; após um estudo, começam a viabilizar o design de peças individuais e levam ao grupo para discutir quais as peças entrarão para fazer parte da coleção. Essas peças são montadas, catalogadas e encomendados modelos para a exposição em eventos de negócios.

Os pedidos de compras geralmente são feitos após as Feiras Internacionais, as exposições dos produtos para o mercado alvo é um grande atrativo e possibilita o fechamento de muitos negócios. As entregas das mercadorias aos importadores ocorrem na maioria das vezes entre novembro e março, pois como o verão europeu tem início em julho, as peças já começam a ser vendidas no exterior em abril.

Para viabilizar as vendas em Feiras, o produto precisa ser diferenciado, e possuir um alto valor agregado, visto que participam mais de mil empresas de vários países, apresentando diferentes conceitos, modelagens, padrões de cores, assessórios, entre outros, dessa forma a concorrência é acirrada. A cultura brasileira se destaca, por ser um país litorâneo, cujo mercado interno adquire grande quantidade de peças para o verão, colaborando com a imagem dos produtos de moda praia no exterior.

A Cooperativa tem assessoria de uma Trading Company que faz os contatos externos, acerta pedidos de compra, de frete, de modal, entre outras características específicas da exportação, e ainda o pós-embarque, ou logística reversa, como pesquisas de satisfação dos clientes, se desejam mais peças, entre outros.

Os mercados para onde já exportaram são: Portugal, Espanha, Alemanha, Itália, Rússia e Líbano. A Cooperativa faz planos de internacionalização, buscando tendências do mercado, influências externas, moldes, sempre atualizado para a moda brasileira, por fazer muito sucesso no exterior, além do alto padrão de qualidade, costura e design diferenciado, pois as exigências no mercado externo são elevadas.

As peças para o mercado externo custam entre EUR 10,00 a EUR 20,00, e trabalham com catálogos da marca, buscando sempre diversificar suas coleções para atender todos os possíveis mercados. Por serem produtos diferenciados e de alta qualidade, seus clientes no mercado internacional são butiques de classe econômica alta, com peças feitas sob encomenda e de alto valor agregado.

A cooperativa exporta geralmente por modal aéreo ou via Exporta Fácil ${ }^{1}$, predominando as modalidades de pagamento parte antecipada e outra à vista com liquidações de câmbio pelo Banco do Brasil. Os principais Incoterms utilizados nas negociações são FCA - Livre no Transportador -, CFR - Custo e Frete-, e CIP - Transporte e Seguro pagos até.

O modal aéreo é o mais utilizado por atender as necessidades dos importadores. As peças demoram muito tempo para serem produzidas desde sua concepção, dessa forma, via aérea demora cerca de 8 dias para chegar ao destino, e pode ser enviada em qualquer quantidade, diferente do modal marítimo, que apesar de mais econômico, demora cerca de 2 a 3 meses para chegar ao destino, e dificilmente a produção de peças de banho conseguirá fechar um container. 
Percebe-se que a escolha do transporte internacional influencia diretamente nos contratos de compra e venda, pois a eficiência da entrega da quantidade celebrada e os prazos são determinantes para o sucesso ou fracasso da negociação.

\section{ATIVIDADE EXPORTADORA}

Toda produção da cooperativa é voltada para o mercado externo. Como dito anteriormente, essa produção é desenvolvida em um período de 3 a 6 meses e é fabricada conjuntamente com a produção das empresas individuais - considerado como negócio paralelo -, o que dificulta muito, pois são dois empreendimentos a serem gerenciados e as empresas cooperadas funcionam como empresas terceirizadas da cooperativa para atender ao mercado externo.

A produção não possui estoque, apenas trabalham com Feiras e Rodadas de Negócios, nos quais são mostradas as coleções e os catálogos, feitos exclusivamente sob encomenda, destinadas ao importador.

Por possuir assessoria de uma Trading Internacional, todos os contatos com os importadores são feitos diretamente pela Trading, que possui os cadastros de clientes fixos e trabalham na busca de novos contatos, e também a cooperativa possui endereço eletrônico: http://www.cactusbrasil.com.br com catálogos on line, informações da cooperativa e contatos.

A Cooperativa não utiliza contrato fixo com empresas de transporte internacional, mas conhece as empresas que fazem as rotas necessárias e deixam a cargo da Trading o fechamento de contrato com as mesmas, atendendo às necessidades dos importadores. Quanto ao transporte nacional, na maioria das vezes contratam empresas locais que se responsabilizam por pegar a mercadoria nos locais de produção e levá-las ao local de embarque, pois a cooperativa não possui transporte próprio.

Os lucros, bem como a produção são divididos igualmente para cada empresa do grupo. Caso hajam 5 pedidos de 200 peças, todas as empresas irão fabricá-las em número igual e divisão igual de lucros.

Para estipular o preço da mercadoria, são repassados para as peças os preços dos tecidos, acessórios, bordados, pinturas, mão-de-obra, entre outros, além da carga tributária, principalmente o ICMS, que conta com a redução do programa Super Simples - estabelece normas gerais relativas ao tratamento tributário diferenciado e favorecido a ser dispensado às microempresas e empresas de pequeno porte - de $17 \%$ para $10 \%$-; por meio desses preços forma-se uma planilha e é acrescentado o lucro da mercadoria, chegando ao preço final, repassado ao importador.

A maior barreira à maior inserção de produtos competitivos no mercado internacional frente à concorrência é a alta carga tributária que o Brasil possui, e o não incentivo por parte do Estado do Rio Grande do Norte para melhores condições de produção. Enquanto o produto da Cooperativa no RN é vendido entre EUR 10,00 a EUR 20,00 no Ceará o produto é vendido por cerca de EUR 4, o que dificulta muito a concorrência. Dessa forma, as empresas têm que se destacarem em outros critérios, como produtos diferenciados, 
bordados, assessórios, condições melhores de venda, prazos, descontos, e outras formas de atrair e principalmente de manter o cliente.

A logística dentro do contexto da formação do preço final da mercadoria não é muito pensada ou direcionada, mas é repassada para o produto aleatoriamente. Custos como frete nacional para aquisição de insumos, locomoção de uma empresa à outra, entre outros, não são exatamente calculados.

\section{EMPRESAS COOPERADAS}

De acordo com os entrevistados, todas as empresas do grupo se desenvolveram de forma empreendedora, com oportunidades de mercado, e ainda, acreditam que por sua localização ser em uma cidade litorânea, o produto é bem aceito. Por ser Natal uma cidade turística a visibilidade do produto pelos estrangeiros é grande, o que gera alguns negócios, pois os turistas levam mercadorias para vender no exterior se tornando representante da marca, mas depois da formação da cooperativa as empresas só enviam produtos ao exterior com a marca da Cactus Brasil.

Quanto aos fornecedores, todas as empresas adquirem dos mesmos, tanto para os produtos destinados ao mercado local e nacional - empresas de forma individual - quanto os produtos da Cooperativa - mercado internacional. Possuem cerca de 5 fornecedores fixos para tecidos e lycra e 3 para assessórios, todos localizados em outros estados. A Cooperativa e as empresas, pelo volume de compras e frequiência, possuem poder de barganha por meio de descontos e facilidades de pagamento.

As empresas de forma individual produzem cerca de 2000 a 6000 peças por mês, destinando entre $20 \%$ a $55 \%$ para a Cooperativa, conseqüentemente, para o mercado internacional. Não possuem estoque, visto que toda produção é feita sob encomenda, mas como atuam também no mercado local, com suas próprias marcas, possuem estoque manual e vendas sob encomendas, com representantes em outros estados como Paraíba e Brasília.

Os empresários fazem previsões de vendas por estação, e lançam cerca de 2 coleções ao ano. As coleções são idealizadas pelos próprios empreendedores, nenhum possui formação em moda, mas são experientes e estão sempre em busca das tendências da moda, dos moldes, dos acessórios, do mercado internacional, entre outros, o que direciona o sucesso do empreendimento.

No Brasil, em especial as cidades litorâneas, se vende biquínis o ano todo, embora nos meses de dezembro a fevereiro, e de julho a agosto, sejam considerados alta estação, o que garante uma manutenção pelo ano, e ainda as empresas trabalham com fitness, roupas para ginástica, e iniciando outros nichos de mercado, como roupa feminina.

Segundo os entrevistados, o sucesso da cooperativa no mercado internacional deve-se ao fato de saber aproveitar as oportunidades, tendo conhecimento do mercado e público alvo, boa administração, criatividade e capital próprio, e as maiores dificuldades são a mão-deobra não qualificada e financiamentos. 
Os principais motivos das empresas para se inserir no mercado internacional, citadas pelos entrevistados foram: diversificar seus mercados, aprender com estrangeiros, melhorar possibilidades de parcerias, maiores incentivos governamentais, melhores margens de lucros, e vender excedente da produção, o que não acontece mais por vender somente por encomenda.

\section{CONSIDERAÇÕES FINAIS E RECOMENDAÇÕES}

A logística é fator relevante para o comércio nacional e internacional influenciando as principais tomadas de decisões das empresas, desde a gestão da cadeia de suprimento até a escolha do canal de distribuição e o cliente, nessa perspectiva, a otimização dos processos logísticos convergem com o sistema de cooperativas como alternativas, pois apóiam as vendas de mercadorias.

É importante frisar que a logística deve ser voltada para atender da melhor maneira possível o cliente, principalmente com relação aos prazos de entrega de produtos, no caso em estudo, visto que a venda de moda praia, a entrega não pode ser postergada, pois a estação influencia fundamentalmente a comercialização.

E ainda, a logística interna pode ser um fator diferencial entre os concorrentes do mesmo segmento, por conseguir diminuir os custos por meio de uma produção eficaz, evitando desperdícios e alocando os recursos da melhor maneira possível, trazendo vantagem competitiva, que as empresas devem poder aproveitar.

Foi identificado na pesquisa que as questões logísticas são imprescindíveis para o fechamento de contratos internacionais dando continuidade às operações de vendas para o mercado externo e permanência nele. A cooperativa sempre está em busca de diferenciar seu produto dos demais, agregando valor às peças atraindo uma clientela mais elitizada.

Verificou-se também na pesquisa, que a Cactus Brasil, apesar de ser uma empresa exclusivamente voltada para a exportação, investe em gerenciar com qualidade os aspectos gerais das formas de negócio com fornecedores de matéria-prima, fabricação, embalagens, suprimentos, armazenamento, manuseio, transportes, mão-de-obra entre outros, ligados às atividades primárias e de apoio da logística.

Visualizou-se com o estudo na Cooperativa, que a teoria está aliada à prática, pois as vantagens de se associar para exportar, com uma atividade econômica pode-se gerar maiores lucros, aumentando a escala de produção, maior número de clientes e conseqüentemente de pedidos, auferem maior poder de barganha com fornecedores; reduzem custos administrativos, operacionais e tributários, dentre outros característicos dessa formação de empreendimento, como visto anteriormente.

Dentre seus pontos fortes destacam-se: planejamento de ações, diversificação de produtos, criatividade, inovação tecnológica e mercado alvo definido. Já seus pontos a melhorar podem-se destacar: administração imparcial, logística interna e custos repassados aos produtos. 
A Cactus Brasil se mostrou uma empresa centrada, voltada para a prática do comércio internacional, superando as barreiras burocráticas e culturais, inserindo cada vez mais seus produtos em diferentes mercados.

Ao mesmo tempo em que fortalece a marca no mercado internacional e nacional, gera um contexto de negócio bem sucedido, levando o nome do país além das fronteiras geográficas, atraindo novos investimentos na área, e elevando a participação do segmento na economia local e nacional.

Por fim, considerou-se que o debate teórico e prático acerca das questões logísticas faz parte de todo planejamento da cadeia de produção, desde o momento da concepção da idéia do produto, até sua confecção - logística interna - e da entrega ao cliente estrangeiro - logística externa, e ainda a logística reversa.

Espera-se com este trabalho, poder ter contribuído acervo bibliográfico sobre Logística de Cooperativas, tendo uma abordagem prática do assunto; direcionado para o mercado internacional, proporcionando aos leitores a possibilidade de identificar ações que separam o sucesso do fracasso deste tipo de empreendimento, voltado exclusivamente para atender às necessidades dos importadores. $\mathrm{E}$ ainda, que se desperte um senso crítico de que não é prudente acomodar-se com o mercado quando gera lucros, pois o mesmo muda constantemente e a variação cambial, caso não esteja atrelada a demais fatores, não resguardará a permanência do produto no mercado externo. Deve-se sempre estar atendo às expectativas do mercado inovando a menores custos, com melhores prazos, e qualidade cada vez mais elevadas.

\section{REFERÊNCIAS BIBLIOGRÁFICAS}

1. BALLOU, Ronald H. Logística Empresarial: transportes, administração de materiais e distribuição física. São Paulo: Atlas, 1993.

2. BRASIL. Federação das Indústrias do Estado do Rio Grande do Norte. Disponível em:

<http://www.fiern.org.br/images/PDF/CIN/Dados_Estatisticos/exportacoes_rn_2007.pdf>

Acesso em: 21 mar-2009.

3. BRASIL. Instituto de Movimentação e Armazenagem de Materiais. Disponível em: <http://www.imam.com.br/>. Acesso em 22: jul-2008.

4. BRASIL. Ministério do Desenvolvimento da Indústria e Comércio. Disponível em: <http://www.mdic.org.com.br>. Acesso em: 12 dez-2007.

5. BRASIL. Serviço de Apoio às Micro e Pequenas Empresas. Lei Complementar $\mathbf{n}^{\mathbf{0}} \mathbf{1 2 3}$ de 14 dez de 2006. Disponível em: <http://www.sebrae.com.br/customizado/lei-geral/leigeral/lei-na-integra>. Acesso em: 26 jul-2008.

6. CAMELO, Gerda Lúcia Pinheiro. et all. Variáveis Externas e suas Repercussões nas Micro e Pequenas Empresas do Rio Grande do Norte. In: Congresso de Pesquisa e Inovação Tecnológica da Rede Norte e Nordeste de Educação Tecnológicas (2., 2007). Disponível 
<http://www.redenet.edu.br/publicacoes/arquivos/20071220_163554_COME-031.pdf.> Acesso em: 15 jul-2008.

7. CHING, H. Y. Gestão de estoques na cadeia de logística integrada. São Paulo: Atlas, 1999.

8. CHRISTOPHER, Martin. Logística e Gerenciamento da Cadeia de Suprimentos. São Paulo. Futura. 1997.

9. DICIONÁRIO MICHAELLIS. Rio de Janeiro: Nova Fronteira, 1997.

10. INCOTERMS 2000. São Paulo: Aduaneiras, 2006.

11. KEEDI, Samir. Logística de Transporte Internacional: veículo prático de competitividade. 2 ed. São Paulo: Aduaneiras, 2004.

12. KOTLER, P. Administração de marketing: a edição do novo milênio. São Paulo: Printice Hall, 2000. 